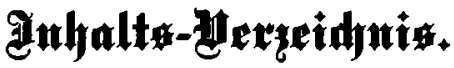

\section{I. (Geridtgvollsieherordnung.}

I. Organifation

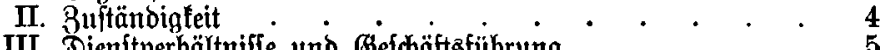

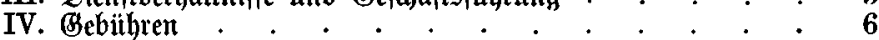

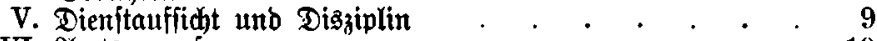

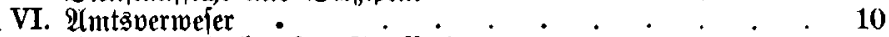

VII. Geridht3vollzieher für Strafiadhen . . . . . . 11

VIII. Sđhluß: unb itbergangabeitimmungen . . . . . 12

\section{Grbiibrentordnungen fiir dir Geridtswollzicher. 15}

I. Reidjągebührentorbmung vom 24 . Juni 1878 in ber F̧affung ber Befarntmadjung vom 20. Mai 1898 . . . 15

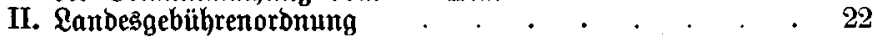

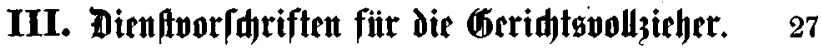

I. $\mathfrak{A b j a h n . ~ B o r b e r e i t u n g a b i e n i t ~ u n d ~}$ Brüfung . . . . 27

II. " Allgemeine $\mathfrak{B}$ oridhriften über bie Dientfführung . 37

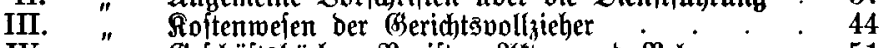

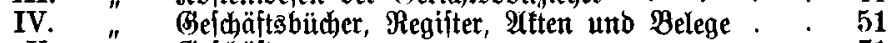

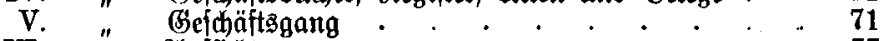

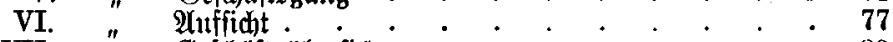

VII. " Gefdä̂tsüberfidten : . . . . 80

VIII. " ưbergangs" und Sd)luks:Beitimmungen . . . 83

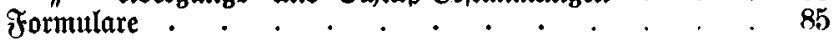

\section{IV. (be/d)äftganwei/ung für die (beridtgvollz̨ieher. 109}

I. Bultellungen . . . . . . . . . . . 110

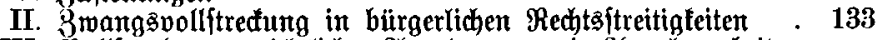

III. Bollftreefung gerichtlidher $\mathfrak{A}$ norbnungen in 2 Angelegenbeiten ber freimilligen Beridtsabarteit . . . . 216

IV. Bwangswollftreftung in Berwaltungsiachen und Bermals

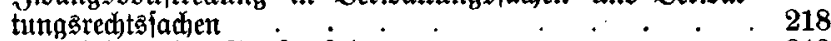

V. Mitmirfung im Strafverfabren . . . . . . 219

VI. Berfteigerung und freihändiger Bertauf aukerhalb ber Bmangsoollftrectung 

Sette.

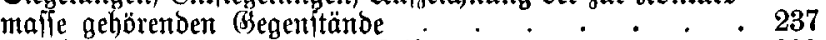

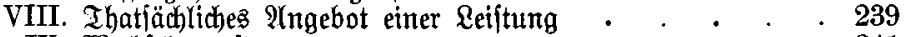

IX. Wechlelprotelte . • . • . . . . • . . 241

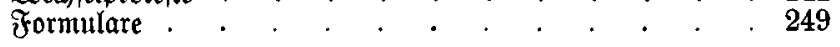

\section{Anthang.}

I. Brkanntmadung vom 16. Dr\}br. 1899, dir Xutsfiil)rumg Der Buftellumgen won Amtswrgen betr. 275

I. Fälle ber $3 u$ iftellung von $\mathfrak{A}$ mtstwegen . . . . . 275

II. Sultellungen in bürgerlichen Redhtştreitigleiten und im

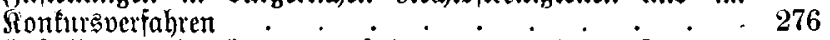

III. Butellungen im Bwangšerfteigerungs: und im Bwangs:

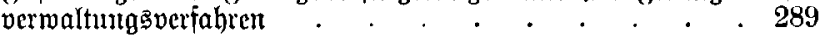

IV. Buitellungen in (Giunbbuthfachen . . . . . . 290

V. Butfellungen in ben angelegenbeiten ber freimilligen Ge: richtsbarfeit . . . . . . , . , 290

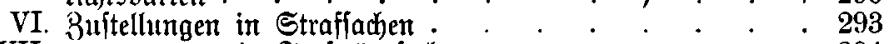

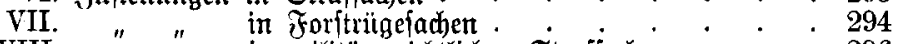

VIII. " " " in militärgeridhtliduen Strafiachen . . . 296

IX. " " in Den Befängniffen ber ₹ujtizvermaltung . 297

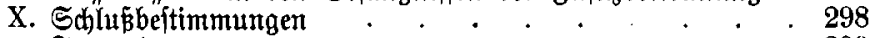

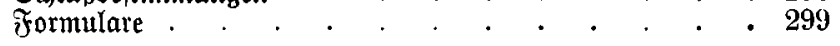

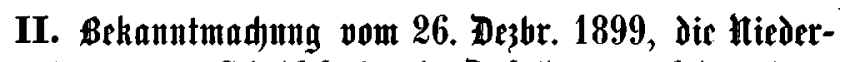

legung von \$dpriftftiiden im Buffrllnugguctfahren betr. 313

\section{Die einfad)ften Begriffe des Wed)/elredts 317}

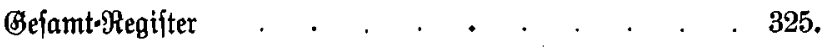




\section{Beridftignutg:}

Seite 218 in Der $\mathfrak{H e b e r i d j r i f t : ~}$

IV. Ftatt VI. 
